\title{
O ENSINO E A APRENDIZAGEM DE LÍNgUa ESTRANGEIRA: ALGUMAS QUESTÓES SOBRE O CORPO
}

\author{
Silvana Matias Freire* \\ Newton Murce ${ }^{* *}$
}

E acontece o seguinte: quando estranho a pintura, ai é que é pintura, e quando estranho a palavra, aí é que ela alcança o sentido, e quando estranho a vida, aí é que começa a vida.

Clarice Lispector

\section{Resumo}

O objetivo deste texto é trazer algumas questóes sobre o processo de ensino e aprendizagem de línguas estrangeiras, levando-se em consideração uma concepção de corpo fundamentada na psicanálise, que o concebe como efeito de linguagem ou corpo pulsional, corpolinguagem.

PalaVras-Chave: Ensino, língua estrangeira, corpo, psicanálise.

\section{Teaching and learning foreign languages: some questions on the body}

\section{AbStract}

The aim of this text is to present some questions about the process of teaching and learning foreign languages, taking into account a conception of body based on psychoanalysis, according to which the body is conceived as effect of language or pulsional body, body language.

KEY WORDS: Teaching, foreign language, body, psychoanalysis.

O objetivo deste texto é trazer algumas questôes sobre o ensino e a aprendizagem de línguas estrangeiras, especialmente no que concerne a uma concepção de corpo fundamentada na psicanálise, que o concebe como corpo pulsional ou corpolinguagem, corpo efeito de linguagem.

As inquietaçóes que levaram à escrita do trabalho baseiam-se nas observaçóes e experiências de seus autores, como professores de língua estrangeira e também como pesquisadores da área.

\footnotetext{
Professora de Língua Francesa no Centro de Ensino e Pesquisa Aplicada à Educação (Cepae/UFG). Doutora em Linguística pela Unicamp. E-mail: silvfreire@ig.com.br.

** Professor de Língua Inglesa do Cepae/UFG. Doutor em Linguística pela Unicamp. E-mail: newtonmurce@yahoo.com.br.
} 
Dentre essas observaçôes, experiências e pesquisas, pode-se destacar, por exemplo, a frustração, muito comum entre professores, em relação a uma expectativa não alcançada por parte de seus alunos, o que não se restringe, evidentemente, às aulas de língua estrangeira (LE), mas à educação em geral. Outro exemplo, que diz respeito aos livros didáticos para o ensino de LE, é que não se percebe nenhuma referência ao corpo que vá além do que este comporta do registro do imaginário, isto é, do que concerne ao campo do sentido. O corpo é basicamente um corpo utilitário, assim como a língua é meramente um "instrumento de comunicação". Daí a LE vai "servir para" o aluno aprender "como" comprar um bilhete numa estação, como pedir comida em um restaurante, como orientar-se dentro de uma cidade desconhecida etc. Os textos também muitas vezes são utilizados como pré-textos "para" alguma coisa, antes de serem considerados por eles mesmos, como fruição, por exemplo. Claro que esses conteúdos também são importantes, mas não são tudo. Aprender uma LE é muito mais complexo - ou muito simples, para alguns -, é verdade, mas, de qualquer modo, não é sem consequências para o corpo.

De uma maneira geral, há uma grande preocupação, tanto nos livros didáticos quanto na própria sala de aula, com o que deve haver de uma (im)possível "garantia" de comunicação, como se a língua fosse transparente, completa, sem equívoco, como se não houvesse corpo desejante e, portanto, a falta constitutiva do sujeito, a incompletude, como se náo houvesse singularidade, como se não houvesse sofrimento ao aprender uma nova língua. A título de exemplos do dia-a-dia escolar, perguntamos: por que a produção de um dado som é impossível ou tão incômoda para um estudante e não para outro (o "th" inglês, por exemplo)?; por que, para alguns, ouvir alguém falando espanhol, que parece tão familiar ao português, pode ser tão incômodo, angustiante?; por que o francês pode remeter ao belo - "francês é tão bonito", comumente ouvimos esse comentário -, ou a algo prazeroso ao ouvido?; por que, de uma hora para outra, um aluno de Ensino Fundamental póe-se a ler compulsivamente livros em francês sem ser exigido pela professora?

Enfim, são perguntas e observaçóes como essas que nos levam, auxiliados por alguns trabalhos significativos já realizados na área (Revuz, 1998; Moraes, 1999; Veras, 2008), a trazer algumas questóes sobre o corpo que possam conduzir à reflexão. 


\section{SOBRE EDUCAÇÃO E PSICANÁLISE}

Há trabalhos recentes que tratam do tema educação e psicanálise, tais como Azenha (2007), De Lemos (2007), Veras (2008), Vorcaro (2008), Lajonquière (1999), Camargo (2006), Voltolini (2007).

No entanto, é importante retornar ao autor que fundou tal discussão para melhor compreender o modo como as pesquisas recentes tratam do tema e, com essa compreensão, oferecer possíveis contribuiçôes. Em 1925, Freud aborda a questão das aplicaçóes da psicanálise na educação e mostra muita cautela em fazer tal aproximação, afirmando que "o trabalho da educação é algo sui generis: não deve ser confundido com a influência psicanalítica e não pode ser substituído por ela [...]. Tal substituição não só é impossível em fundamentos práticos, como também deve ser desaconselhada por razóes teóricas" (Freud, 1925, p. 308).

Freud alerta ainda que se a psicanálise pode propiciar algum benefício à educaçáo, isso ocorre se o educador se submete a uma análise e a experimenta em si mesmo, pois essa experiência lhe daria uma possibilidade de maior insight sobre o infantil.

A concepção freudiana de educação escolar não se distingue da educação da criança pelos pais, pois ambas visam à transmissão cultural impondo a renúncia às pulsóes. Nas palavras da psicanalista De Lemos (2007, p. 84): "a concepção freudiana da educação impressiona por sua total desconsideração pelos ideais pedagógicos: trata-se de fazer com que a criança aprenda a controlar suas pulsóes e ponto final!".

Isso não significa desmerecer o empreendimento educativo, mas mostrar que a educação tem como missão inarredável inibir, proibir, suprimir e direcionar as pulsôes. A não realização dessa missão implica uma renúncia ao ato educativo. As aplicaçóes da psicanálise no campo da educação apontam para essa renúncia (ou para a resistência à psicanálise).

A função recalcante e inibidora da educação é, por outro lado, uma condiçâao propícia para despertar desejo no sujeito, ou seja, sem a operação de interdição das pulsôes, o desejo (de conhecer) não comparece. Freud idealiza, porém, um ponto 'ótimo' ao qual a educação deve atingir:

A educação tem de escolher seu caminho entre o Sila da náo-interferência e o Caríbdis da frustração [...]. Deve-se descobrir um ponto ótimo que possibilite à educaçáo atingir o máximo com o mínimo de dano. Será, 
76 Revista Solta a Voz, v. 20, n. 1

portanto, uma questão de decidir quanto proibir, em que hora e por que meios (Freud, 1932, p. 147).

Eis o desafio com o qual o professor se defronta em seu cotidiano. Como instaurar o desejo de aprender no aluno - desejo inexistente na criança, segundo Freud - a partir da operação de interdição? De Lemos (2007, p. 87) indica que a condição para engajar o aluno numa via desejante não está no desejo de educar do professor, está no fato de que o desejo do professor se dirija para Outro lugar: "É assim quando, por exemplo, o desejo do professor é causado mais pela Matemática do que pela necessidade de reencontrar no aluno os sinais de confirmação de que sua mensagem foi recebida sem deformaçóes" (De Lemos, 2007, p. 87).

Uma alternativa que evitaria o recalcamento ou a inibição das pulsôes é o desvio destas pela via da sublimação. Daí lembrarmos a importância de uma experiência com a literatura, a música, a pintura, o teatro, por exemplo, como meios de os alunos entrarem em contato com a produção humana que resulta do desvio das pulsôes. Contato que se dá corporalmente, isto é, como olhar, voz, escuta, movimento.

\section{O QUE SE MOBILIZA QUANDO SE APRENDE UMA LE}

Há significativos trabalhos sobre a complexidade do que está envolvido nas dicotomias familiar/estrangeiro (Freud, 1919), língua materna/ língua estrangeira (Moraes, 1999; Veras, 2008), mesmo nos textos presentes neste volume (Barichello, Moraes), mas para o momento, o texto de Revuz (1998) é bastante esclarecedor.

Para ela, a aprendizagem de LE vem questionar a relação que está instaurada entre o sujeito e sua língua. A pesquisadora (1998, p. 216-217) aborda a complexidade e a dificuldade de se aprender LE, que "solicita o sujeito, seu modo de relacionar-se com os outros e com o mundo: prática corporal, ela póe em jogo todo o aparelho fonador". Essa aprendizagem mobiliza dimensôes da pessoa que geralmente não colaboram, nem mesmo convivem, em harmonia. O sujeito põe a serviço da expressão de seu eu um vaivém que requer muita flexibilidade psíquica entre um trabalho de corpo sobre os ritmos, os sons, as curvas entoacionais, e um trabalho de análise e de memorização das estruturas linguísticas: "muitos dos insucessos podem ser analisados como uma incapacidade de ligar essas 
três dimensôes: afirmação do $e \mathcal{U}$, trabalho do corpo, dimensão cognitiva" (Revuz, 1998, p. 217).

Aprender LE é complexo porque solicita, ao mesmo tempo, nossa relaçáo com o saber, com o corpo e com nós mesmos como sujeitos falantes. Além disso, solicita as bases de nossa estruturaçáo psíquica e, com elas, aquilo que é, ao mesmo tempo, o instrumento e a matéria dessa estruturação, ou seja, a linguagem, a língua chamada materna. Portanto, "toda tentativa para aprender uma outra língua vem perturbar, questionar, modificar aquilo que está inscrito em nós com as palavras dessa primeira língua” (Revuz, 1998, p. 217). Antes de ser objeto de conhecimento, a língua é o material fundador de nosso psiquismo e de nossa vida relacional, daí que a língua não é mero instrumento de comunicação. A língua causa sujeito. Somos efeito de linguagem. Da estreita "relação" entre corpo e LE, a autora (1998, p. 219) afirma:

A descoberta das palavras, das significaçóes lingüísticas é indissociável da experiência da relação com o outro e das significações libidinais que se inscrevem nela. A voz, as palavras da mãe são fontes de prazer ou de desprazer; elas têm, além disso, o poder de interferir nas outras sensaçóes (visão, tato, paladar) reforçando ou anulando os sentimentos de prazer ou de desgosto que são ligados a elas.

O sofrimento que constitui uma experiência de aprendizagem é abordado por Revuz (1998, p. 230) nos seguintes termos:

Mais que em problemas técnicos, a aprendizagem de LEs esbarra na dificuldade que há para cada um de nós, não somente de aceitar a diferença mas de explorá-la, de fazê-la sua, admitindo a possibilidade de despertar os jogos complexos de sua própria diferença interna, da não coincidência de si consigo, de si com os outros, de aquilo que se diz com aquilo que se desejaria dizer.

Sobre os obstáculos aos aprendizes, que podem se manifestar por meio de dificuldades de jogar de modo diferente com a música, com a acentuação, sons, ritmos ou sobre os sucessos, isto é, para aqueles que se apropriam com facilidade da música outra, do significante, a autora (1998, p. 220) aponta a seguinte hipótese:

isso (fracasso ou sucesso) constitui indício de alguma coisa do funcionamento psíquico do sujeito. Ainda que ponderando que seria desatino 
emitir interpretaçóes sobre as dificuldades dos aprendizes, pode-se ajudar a superá-las, remetendo-as não a um estado de fato ("tenho a memória ruim", "não posso pronunciar este som", "não compreendo gramática"), mas a "um sentido, a uma história singular com a língua. A cada um corresponde, em seguida, decifrar esse sentido, se assim o desejar".

Há uma frase de Revuz (1998, p. 227) que resume muito bem o que ela desenvolve ao longo de seu artigo e que para nós é especialmente significativa: "aprender uma língua é sempre, um pouco, tornar-se um outro".

A aprendizagem de uma língua estrangeira tem como referência a língua materna, no que elas se aproximam ou distanciam (sons e sentidos diferentes ou parecidos, mesma raiz etimológica). A língua materna, não sabemos dizer como foi que a aprendemos, parece-nos, quase sempre, que ela nunca foi aprendida: "Esse estar-já-aí da primeira língua é um dado ineludível, mas essa língua é tão onipresente na vida do sujeito, que se tem o sentimento de jamais tê-la aprendido, e o encontro com uma outra língua aparece efetivamente como uma experiência totalmente nova” (Revuz, 1998, p. 215).

Náo podemos dar o testemunho de como aprendemos a língua materna. Podemos, no entanto, supor como isso se deu. Podemos supor que, de início, a aquisição da língua materna não se dá 'naturalmente', mas é resultado de um ensino em que, se não se exige um local e hora marcados e conteúdos definidos como o que ocorre na escola, não prescinde de um esforço do lado do infans (não falante) e imposições de regras do lado do Outro. Nas palavras de Freud (1905, p. 122-123):

O período em que uma criança adquire o vocabulário da língua materna proporciona-lhe um óbvio prazer de 'experimentá-lo brincando com ele', segundo as palavras de Gross [p. 125]. Reúne as palavras, sem respeitar a condição de que elas façam sentido, a fim de obter delas um gratificante efeito de ritmo ou de rima. Pouco a pouco esse prazer vai lhe sendo proibido até que só restam permitidas as combinaçóes significativas de palavras.

Por outro lado, a língua estrangeira usualmente exige mediações pedagógicas e técnicas e se dá em um tempo em que o sujeito tem condiçôes simbólicas de verbalizar sua experiência de aprendizagem - dificuldades, dúvidas etc. No entanto, o fracasso é mais frequente.

Se há sofrimento, resistência, perda e ganho de prazer na aquisição da língua materna, podemos supor que o encontro com uma LE vai atualizar 
tais sentimentos no sujeito aprendiz: "Toda tentativa para aprender uma outra língua vem perturbar, questionar, modificar aquilo que está inscrito em nós com as palavras dessa primeira língua. Muito antes de ser objeto de conhecimento, a língua é o material fundador de nosso psiquismo e de nossa vida relacional" (Revuz, 1998, p. 217).

\section{Corpo e SENTIDO}

O que pode estar em jogo na aprendizagem de uma língua estrangeira é como o aprendiz lida com a rememoração de sua condição de infans, ou seja, de sua condiçấo de não falante que um dia ele teria sido. Nessa condição, o que a criança ouve é uma voz

plena de música, que introduz na criança o sopro criador de falantes, e a criança recebe de sua máe essas vibraçóes harmônicas, cintilantes, mutantes, da fala - acordossom [...]. Esse momento zero da chegada do sujeito é marcada pelo esquecimento, recoberto, apagado pela entrada do sujeito na linguagem (Veras, 2008, p. 117).

Essa fala não pode ainda ser recortada em sequências sonoras pelo sujeito, ou seja, em palavras que fazem sentido. Segundo Pommier (2004, p. 144), nos primeiros encontros com uma LE só se pode escutar a música

de uma língua estrangeira que não compreendemos, ouvimos primeiro um fonetismo que não percebemos mais em nossa língua, ocupados que estamos pela significação do que exprimimos. Escutando uma língua incompreensível, ouvimos sons tão estranhos quanto aqueles da primeira música, da qual perdemos a memória atribuindo às palavras um sentido. A língua estrangeira evoca este gozo perdido. Pela via da sonoridade, ela nos toca, nos desagrada ou, ao contrário, nos seduz. (tradução nossa)

A LE evoca no aprendiz aquele momento que Freud descreve: momento em que se brincava com os sons sem se preocupar em fazê-los significar. Mas, o que o som sem sentido implica? Implica que se náo temos o sentido para reter a nossa atenção, o que se coloca em primeiro plano é um corpo que profere sons. É na ausência de sentido que o corpo se faz presente, é o corpo que atua e se coloca em primeiro plano. Ao privilegiar o "como se diz" (forma), em detrimento de "o que se diz" (conteúdo), deixa- 
mos de lado o sentido: "O que fica em evidência, assumindo um primeiro plano, é o som da própria voz [...] e a performance (não a da retórica: num discurso em que o sentido não está excluído, o que se diz e como se diz não se separam) dos órgãos que se colocam em funcionamento nesta produção vocal" (Freire, 2007).

A experiência esquecida com os sons da língua materna é atualizada nas formas com que os sujeitos aprendizes lidam com a aprendizagem de LE. Reaçôes como rubor, suor, tremor, gagueira, hesitaçôes etc. são comuns em salas de aula de línguas estrangeiras, nos momentos como este: "o aluno que começa a aprender e tem dificuldade em pôr sua língua entre os dentes, porque aquilo que precisa articular não é um fonema de sua língua - ou seja, não serve para distinguir segmentos que façam sentido" (Veras, 2008, p. 116).

Momentos em que, desprovidos da máscara dos sentidos, o corpo fica exposto de forma constrangedora.

\section{Corpo REAL SIMBólico E IMAGINÁRIO}

No início do texto foi mencionado que o corpo que se concebe nos livros didáticos de LE é um corpo mais restrito ao registro do imaginário. Convém esclarecer no que consiste o corpo em psicanálise, corpo efeito de linguagem, corpo que é a um só tempo real, simbólico e imaginário. Isso é importante para podermos entender a complexidade que está envolvida no que Revuz chama de "tornar-se um pouco um outro".

De acordo com a psicanálise, o corpo não é o corpo puramente orgânico, natural, biológico, mas corpo efeito de linguagem. Conforme esclarece Garcia-Roza (1990), não se pretende, no entanto, dizer que o biológico não existe ou desconsiderar a representação imaginária do corpo biológico. O corpo psicanalítico, o corpo pulsional, não é a antítese do biológico, apenas diferente.

Além da dimensão do registro simbólico, o corpo está simultaneamente referido aos registros do imaginário e do real. Esta tripartiçáo estrutural constitui os três registros ou instâncias a partir das quais é possível apreender a experiência do sujeito. Lacan (1974/5) apresenta os três registros dentro da estrutura do nó borromeano, unidos por elos que não podem ser isolados, pois, uma vez desatado qualquer um, os outros se desligam simultaneamente. O nó borromeu possibilitou a Lacan demonstrar que, para que a estrutura se dê, é preciso pelo menos três elementos. 
Resumidamente, o simbólico (S) constitui o campo da linguagem ou do inconsciente estruturado como uma linguagem; o real (R) é o campo do impossível, do que estaria fora da linguagem, constitui o irrepresentável, o resto que sobra da entrada do sujeito na linguagem; o imaginário (I) é o campo da consistência, do sentido, da imagem especular. O real é efeito do simbólico e diz respeito ao campo da Coisa, que é a parte excluída do ser humano quando este, sem identidade, deixa-se representar pelo nome que vem do Outro. É um campo que está além do bem e do mal, campo do "pior", campo de força, de guerra, de gozo, campo do irrepresentável e do intangível. No entanto, campo que tem poder criativo. É por isso que Fingermann (2005) chama Beckett, Duras e Lispector de "passadores do pior" porque nos proporcionam encontros inauditos que nos capturam, deslumbram e mudam nossas vidas. $\mathrm{O}$ registro do real constitui a falta originária da estrutura, o impossível de ser simbolizado. Não é o que se chama de realidade, pois remete justamente ao que escapa a essa realidade, isto é, ao que é da ordem do traumático, do inassimilável, do irrepresentável, enfim, ao que não se inscreve no simbólico. Embora não se inscreva no simbólico, esse real produz efeitos no corpo.

Ao longo de seu ensino, Lacan dá maior ênfase ora para um, ora para outro registro. Teríamos, assim, por exemplo, uma direção que vai do imaginário para o simbólico e deste para o real. É no texto "O estádio do espelho como formador da função do eu" (Lacan, 1949) que ele prioriza o registro do imaginário e o momento inaugural da constituição do $e u$, isto é, momento em que o infans, ou seja, aquele que ainda não fala, consegue perceber sua própria imagem no espelho, que é reconhecida pelo outro como verdadeira, o que dá ao bebê uma sensação de unidade e de contorno nítido, fazendo com que a indiferenciação - entre seu corpo e o de sua mãe - que caracterizava seu corpo despedaçado, transforme-se na imagem de um corpo próprio. Conforme observa Jorge (2000, p. 45), contudo, embora o eu seja descrito aqui como essencialmente imaginário, ele náo prescinde do reconhecimento simbólico do Outro do simbólico, encarnado pelo agente materno. Com o estádio do espelho, Lacan demonstra que o imaginário está submetido ao simbólico, portanto. Dado que o eu traz a ilusão de uma unidade corporal, de uma completude imaginária, o sujeito é excêntrico a ele, uma vez que o sujeito é efeito do simbólico, sendo representado de um significante para outro significante. Essa concepção imaginária de corpo, como uma unidade completa, é predominante quando se fala de corpo, tal como se dá nos livros didáticos de LE. 
Conforme Jorge (2000, p. 46),

O imaginário não é da ordem da mera imaginação e esse registro deve ser entendido como o da relação especular, dual, com seus logros e identificaçôes, mas, sobretudo, segundo os desenvolvimentos finais de Lacan, com o advento do sentido. Já o simbólico é da ordem do duplo sentido, e o real, que não se confunde com a realidade, é o não-senso radical, ou, como diz Lacan, o "sentido em branco" [...]. O simbólico é o registro que permite ao falante mediatizar o encontro com o não-senso do real. (grifos do autor)

Dizer que o corpo é uma realidade é dizer que, "como ela, ele é triplo, simbólico, imaginário e real" (Soler, 1989, p. 3). Conforme lembra a autora, no ensino de Lacan uma constante se impóe, que é a distinção entre o organismo, o vivente e o que a língua designa como corpo. Inicialmente, com o estágio do espelho, ele abordou o corpo pela imagem, isto é, para fazer um corpo é preciso um organismo mais uma imagem. O que dá unidade e pertinência e faz o "um" de um corpo é a consistência da forma, a gestalt visual, oposta ao mal-estar, à deiscência do organismo prematuro que a imagem não ordenou. E desde essa prótese do imaginário, que de um organismo fragmentado faz um corpo unificado, concebe-se que essa imagem oferta-se ao amor e toma seu valor libidinal, que é o narcisismo, segundo Freud. A coesão do vivente, como um organismo individualizado, opóe-se entấo ao corpo despedaçado que a linguagem dá ao ser falante, que não tem, além disso, sua unidade senão do "um" do "significante" (Soler, 1989).

No texto Radiofonia, Lacan (1970, p. 406) trata do corpo do simbólico. E no Discurso de Roma (Lacan, 1953) ele já notava: ele é corpo sutil, mas corpo. Em suas palavras:

Volto primeiro ao corpo do simbólico, que convém entender como nenhuma metáfora. Prova disso é que nada senáo ele isola o corpo, a ser tomado no sentido ingênuo, isto é, aquele sobre o qual o ser que nele se apóia não sabe que é a linguagem que lho confere, a tal ponto que ele náo existiria, se não pudesse falar. (Lacan 1970, p. 406)

O primeiro corpo, então, o corpo do simbólico, corpo incorporal, faz o segundo. E por se incorporar nele, ele nos dá um corpo. Daí não ser sem consequências aprender LE, que é transformar-se um pouco em um outro. O simbólico é corpo, como seus elementos são coordenados em 
um sistema de relaçóes internas. Conforme Soler (1989, p. 8), o corpo do simbólico "se apresenta em duplo sentido: ele nos atribui, mas mais exatamente, ele nos fabrica. O Corpo”.

\section{CONSIDERAÇóEs FinAIS}

Cabe, por fim, retomar algumas questóes que aqui foram expostas, destacando alguns aspectos que nos parecem relevantes. No que diz respeito à história singular de cada um, por exemplo, é importante que o professor se atente não só para o que pode haver de sucesso, mas para o que há de impossível no ato de educar, no que há de fracasso, de falta, de incompletude na relação corpo e língua, porque, de tudo que se passa no processo ensino-aprendizagem, por mais atrativos que se forneçam, há muito mais náo controle do que controle sobre o que se passa com cada sujeito, cada aluno, cada professor, em cada situação, cada dia e por aí vai...

Deve-se lembrar, ou não se esquecer, de que somos nada mais que efeitos de linguagem, efeitos do inconsciente, portanto, deixar-se ser afetado pela língua e pelo que a língua provoca, como corpo (materialidade sonora e plástica) e no corpo, em cada aula e em cada aluno. Corpo entendido não somente no que comporta de imaginário, mas no que há de singular mesmo, corpo composto de zonas erógenas ou libidinais que são menos ou mais ativadas ao se aprender uma LE, de um ou de outro modo para cada sujeito em particular, sujeito que se torna um pouco um outro e que sofre, por vezes, exatamente por isso. Afinal, como que se tornar um pouco um outro pode provocar só prazer? Só lúdico? Num grupo de trinta alunos, por exemplo, quem está disposto a isso? Quem dá conta disso? Que metodologia vai "funcionar" para um e não para outro?

Pode-se perguntar, porém, em contraponto: o que deve fazer o professor, então? Deve, evidentemente, cumprir seu papel de ensinar. Fazer o que considera ser o melhor, das melhores maneiras, como sempre foi dito. Mas sabendo que não há garantias. Não há como garantir que o aluno seja capturado pela língua. Isso simplesmente acontece ou não acontece. Apenas em um tempo posterior é que resultados poderão ser observados. $\mathrm{E}$ essa captura é da ordem do inconsciente. É de cada sujeito.

A língua não é meramente um instrumento de comunicação e o corpo não é só um corpo imaginário que sabe como dizer isso ou aquilo em uma LE. O corpo é real, simbólico e imaginário, o corpo é efeito do real da língua, 
isto é, do que dela há de irrepresentável, que é da ordem do puro som, da voz, do prazer do jogo sem sentido, do jogo poético, musical, plástico. O corpo é efeito do entrelaçamento desses três registros e esses três registros compõem as presenças também reais disso que é um encontro - e um desencontro -, sempre singular e jamais repetível, entre professor e aluno, ou entre aluno e aluno, ou entre um aluno e o próprio aluno, como sujeito dividido que é. Encontro que, em se tratando de uma LE, pode soar especialmente estranho, no entanto, não menos estranho do que o encontro - e o confronto - com a obrigação de tornar-se um sujeito falante, ao se "adquirir" a língua materna.

Tudo o que o professor diz ou silencia, tudo o que faz em sala de aula produz efeitos. E principalmente o que se faz e o que não se sabe que está fazendo e que, no entanto, é passado pela voz, pelo olhar, por uma escuta, uma dada entonaçáo, efeitos que dizem respeito ao real do corpo e para os quais não se tem nome, porque bordejam o irrepresentável, mas que produzem efeitos.

Vale destacar ainda o papel importante da sublimação, o papel fundamental da arte em sala de aula, do poético, da música, do jogo, do humor e do riso. O poético, conforme observado em outro momento (Murce, 2003), por se sustentar no jogo de significantes e por trabalhar com o corpo da expressão, o corpo verbal, o que a palavra tem de coisa e da Coisa, permite, por isso mesmo, a possibilidade do novo, de rupturas, de estranhamento, de espanto, de exploração dos sons de uma língua no que esta, em sua ordem (lei) e (diz!)ordem (desejo), autoriza e desautoriza em termos de jogos metafóricos e metonímicos. Por se produzir no jogo de sons e diferenças, o poético permite que se suspenda o nível do sentido (imaginário), do duplo sentido (simbólico), para se trabalhar no nível do significante e da letra (real) que, por náo se constituir um sentido preestabelecido, afeta o sujeito em sua materialidade sonora, singularmente, no modo como ressoa no corpo. É somente pela via do corpo e no corpo que algo do novo pode afetar o sujeito, convocá-lo, mobilizando-o. O novo (estranho) ressoa no corpo, fazendo sentido ao sujeito, ainda que não se compreenda esse sentido, arrebatando o sujeito, mobilizando-o. A arte (o poético) bordeja o vazio, o irrepresentável, a Coisa, daí produzindo o novo.

Importa trabalhar com o texto em sala de aula não somente no que concerne ao registro do sentido (imaginário), mas no que o texto possui de puro jogo com o significante, com a pura diferença, podendo-se fruir o que esse texto comporta de material plástico, sonoro, a ser manipulado, 
despertando o leitor para um nível que ultrapassa o nível do sentido. Daí a prática teatral poder ser interessante, a memorização e a recitação de textos poéticos, a escrita de textos-colagem, permitindo-se que o aluno viva a língua e que seja surpreendido pela língua, capturado, singularmente.

\section{REFERÊNCIAS}

AZENHA, C. A. C. Professor, não vês que estou queimando? Revista Solta a Voz, Goiânia, Cegraf/UFG, v. 18, n. 1, p. 29-39, 2007.

CAMARGO, A. C. C. S. Educar: Uma questão metodológica? Proposiçóes psicanalíticas sobre o ensinar e o aprender. Petrópolis: Vozes, 2006.

FINGERMANN, D. Os passadores do pior - Beckett, Blanchot, Duras: Travessias. In: FINGERMANN, D.; DIAS, M. M. Por causa do pior. Sáo Paulo: Iluminuras, 2005. p. 93-105.

FREIRE, S. M. Glossolalias: ficção, semblante, utopia. 2007. Tese (Doutorado em Linguística) - Instituto de Estudos da Linguagem, Universidade Estadual de Campinas, Campinas, São Paulo, 2007.

FREUD, S. Os chistes e sua relação com o inconsciente (1905). In:

Obras psicológicas completas de Sigmund Freud. v. VIII. Rio de Janeiro: Imago, 1996.

—. O estranho (1919). In: — Obras psicológicas completas de Sigmund Freud. v. XVII. Rio de Janeiro: Imago, 1996.

GARCIA-ROZA, L. A. O mal radical em Freud. Rio de Janeiro: Jorge Zahar, 1990.

JORGE, M. A. C. Fundamentos da psicanálise: de Freud a Lacan. Rio de Janeiro: Jorge Zahar, 2000.

LACAN, J. O estádio do espelho como formação do eu (1949). In:

Escritos. Rio de Janeiro: Jorge Zahar, 1998. p. 96-103.

—. Função e campo da fala e da linguagem em psicanálise (1953). In:

—. Escritos. Rio de Janeiro: Jorge Zahar, 1998. p.238-324.

$1974 / 5$.

O Seminário, livro 22 - RSI. Ornicar? v. 5. Paris: Le Graphe, 
LACAN, J. Radiofonia (1970). In: . Outros escritos. Rio de Janeiro: Jorge Zahar, 1998. p. 400-447.

LAJONQUIÈRE, L. Infância e ilusão (psico)pedagógica: escritos de psicanálise e educação. Petrópolis: Editora vozes, 1999.

MORAES, M. R. S. Maternalestrangeira: o que Freud fez da língua. 1999. Tese (Doutorado em Linguística) - Instituto de Estudos da Linguagem, Universidade Estadual de Campinas, Campinas, São Paulo, 1999.

MURCE, N. Da escritura ao corpo e do corpo à escritura. Revista Solta a Voz, Goiânia, Cegraf/UFG, v. 14, n. 2, p. 67-74, 2003.

POMMIER, G. Naissance et renaissance de l'ecriture. 2ème triage. Paris: PUF, 2004.

REVUZ, C. A língua estrangeira entre o desejo de um outro lugar e o risco do exílio. Trad. de S. Serrani-Infante. In: SIGNORINI, I. (Org.). Lingua(gem) e identidade. Campinas: Mercado de Letras; São Paulo: Fapesp, 1998. p. 213-230.

SOLER, C. O corpo no ensino de Jacques Lacan. Trad. náo publicada de M. Marinho, F. Fontenelle e L.E. Rosa. Belo Horizonte: Papéis do Simpósio, 1989.

VERAS, V. O e(x)trangeiro na língua materna: (não) desejar as coisas alheias. Revista Solta a Voz, Goiânia, Cegraf/UFG, v. 19, n. 1, p. 111-124, 2008.

VOLTOLINI, R. O discurso do capitalista, a psicanálise e a educação. In: LEITE, N.; AIRES, S., VERAS, V. (Orgs.). Linguagem e gozo. Campinas: Mercado de Letras, 2007. p. 197-212.

VORCARO, A. O que se quer quando se quer ensinar? Texto apresentado no VII Colóquio Linguagem e Educação, 2008. Mimeo.

Recebido em: 18 out. 2008

Aceito em: 15 fev. 2009 